\title{
Anaesthetic management of posterior lumbar osteotomy
}

David G. Wills MD FRCP(C)

Sixty-four cases of posterior lumbar extension osteotomy performed at the Toronto East General Hospital between 1969 and 1983 are reviewed. The anaesthetic management is presented. The procedure was performed with local infiltration anaesthesia, heavy sedation and a brief period of general anaesthesia induced with nitrous oxide, halothane or ketamine. Five stages in the anaesthetic management are distinguished, each in relation to a phase of the surgical procedure and drug usage. A method of supporting these deformed patients in the prone position in moulded plaster casts is described. Anaesthetic and surgical complications and postoperative psychological disturbances are described and discussed. It is suggested that caudal epidural opioid or local anaesthetic analgesia be explored as an aid in the management of these patients.

Key words

SURGERY: lumbar osteotomy; ANAESTHETIC TECHNIQUES: intravenous sedation, general, caudal epidural; ANAESTHETICS, INTRAVENOUS: ketamine; ARTHROPATHIES: ankylosing spondylitis.

From the Department of Anaesthesia, the Toronto East General and Orthopaedic Hospital and the University of Toronto, Toronto, Ontario.

Address correspondence to: Dr. David G. Wills, Department of Anaesthesia, Toronto East General and Orthopaedic Hospital, 825 Coxwell Avenue, Toronto, Ontario, M4C 3E7.

After August 1985: Department of Anaesthesia, The Halifax Infirmary, 1335 Queen Strect, Halifax, Nova Scotia, B3J 2H6.
This report is a retrospective analysis of the anaesthetic management of 64 lumbar extension osteotomies performed on 61 patients for the correction of severe, fixed spinal flexion deformity. All patients acquired their deformity as a consequence of ankylosing spondylitis (AS). AS has been known in the past as von Bechterew's Disease, Marie-Strumpell's disease and more recently as rheumatoid spondylitis. The last designation is inappropriate since AS may be distinguished from rheumatoid disease on clinical and non-clinical grounds. 'However, AS and rheumatoid arthritis (RA) present related problems in anaesthetic management and Edelist's 1964 review, ${ }^{2}$ although entitled "Principles of Anesthetic Management in Rheumatoid Arthritic Patients," remains a classic guide to the anaesthetic management of AS.

AS is the dominant subset of a group of interrelated disorders generally known as the seronegative spondylarthropathies (Figure 1). Clinically, AS is suggested by the insidious onset of back pain, which improves with exercise, in an individual under 40 years of age. Radiologic evidence of sacroiliitis confirms the diagnosis. ${ }^{3}$ Pathologically, changes are concentrated around the sites of ligamentous insertion (enthesis). First inflammation develops, then new bone formation. The disease is said to be primary if no other rheumatologic disorder is present or secondary if related to one of the other spondylarthropathies (Figure 1).

Once thought to be a rare, predominantly male, disease always progressing to spinal fusion, AS is now recognized as common, existing with varying degrees of severity or remaining undiagnosed or incorrectly diagnosed. The sex incidence is thought to be equal but men have the more progressive spinal disease in a clinical ratio of about three to one. The severe flexion deformity, which will 


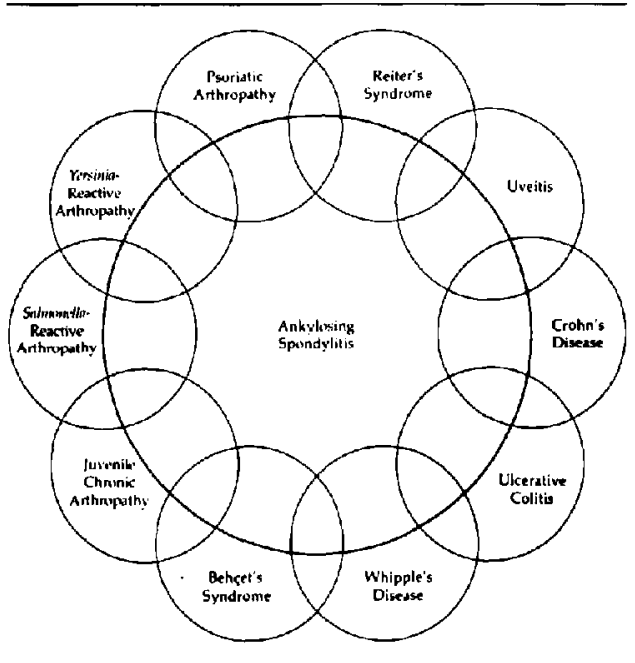

FIGURE 1 The interrelations of the seronegative spondylarthropathies. Fromn ${ }^{3}$, with permission. require surgery, is rare. This report, then, deals with a rare procedure. Fewer than three hundred cases of lumbar extension osteotomy have been reported (Table I). However, AS and RA are not uncommon disorders (each has a prevalence of about one per cent) and patients with clinical or subclinical AS or RA will eventually present in every anaesthetic practice. They may require surgery for conditions entirely unrelated to their disease and their life-threatening airway abnormalities may not be immediately apparent.

\section{History}

The published reports $\mathrm{s}^{4-15}$ in the English language on lumbar osteotomy are summarized in Table $\mathbf{I}$. These are all surgical reports and deal only briefly with the anaesthetic problems. The majority emphasized the need for "general endotracheal anaesthesia" (probably as opposed to general mask anaesthesia) and used the prone position throughour

TABLE I Summary of the literature

\begin{tabular}{|c|c|c|c|c|}
\hline Author & Time period & No. of cases & Type of anaesthesic & Position \\
\hline \multicolumn{5}{|l|}{ Smith-Petersen } \\
\hline $\begin{array}{l}\text { Boston, Mass. } \\
\text { La Chapelle }\end{array}$ & 1941 & 6 & Not mentioned & Prone \\
\hline $\begin{array}{l}\text { Netherlands } \\
\text { (two-stage procedure) }\end{array}$ & 1944 & 1 & Local and general & Prone and lateral \\
\hline Adams & & & & \\
\hline $\begin{array}{l}\text { London, England } \\
\text { Nunziata }\end{array}$ & 1940's & $?$ & General & Lateral \\
\hline $\begin{array}{l}\text { Argentina } \\
\text { Law }\end{array}$ & 1948 & 2 & General & Prone or lateral \\
\hline London, England & 1950 's & 110 & General & Prone \\
\hline $\begin{array}{l}\text { Aix-les-Bains, France } \\
\text { (two-stage procedure) }\end{array}$ & 1950 's & 37 & Local and general & Prone and lateral \\
\hline Lorenzo & & & & \\
\hline $\begin{array}{l}\text { Sao Paulo, Brazil } \\
\text { (anaesthetic management) } \\
\text { Scudese }\end{array}$ & 1950 s & 38 & General & Prone \\
\hline $\begin{array}{l}\text { Jersey City, New Jersey } \\
\text { Goel }\end{array}$ & 1959 & 1 & General & Prone \\
\hline $\begin{array}{l}\text { Lucknow, India } \\
\text { Kallio }\end{array}$ & 1960 's & 15 & General & Prone \\
\hline $\begin{array}{l}\text { Helsinki, Finland } \\
\text { Emneus }\end{array}$ & 1961 & 1 & General & Prone \\
\hline $\begin{array}{l}\text { Lund, Sweden } \\
\text { McMaster, M.J. }\end{array}$ & $1950-1962$ & 5 & Local (3) extradural? (2) & Prone \\
\hline $\begin{array}{l}\text { Mayo Clinic } \\
\text { McMaster, P.E. }\end{array}$ & $1945-1967$ & 17 & General & Prone \\
\hline Beverly Hills, California & $1948-1980$ & 40 & General & Prone \\
\hline Total & & $\overline{273}$ & & \\
\hline
\end{tabular}


TABLE II Outline of the conduct of anaesthesia (drugs in approximate relation to stage of procedure and actions)

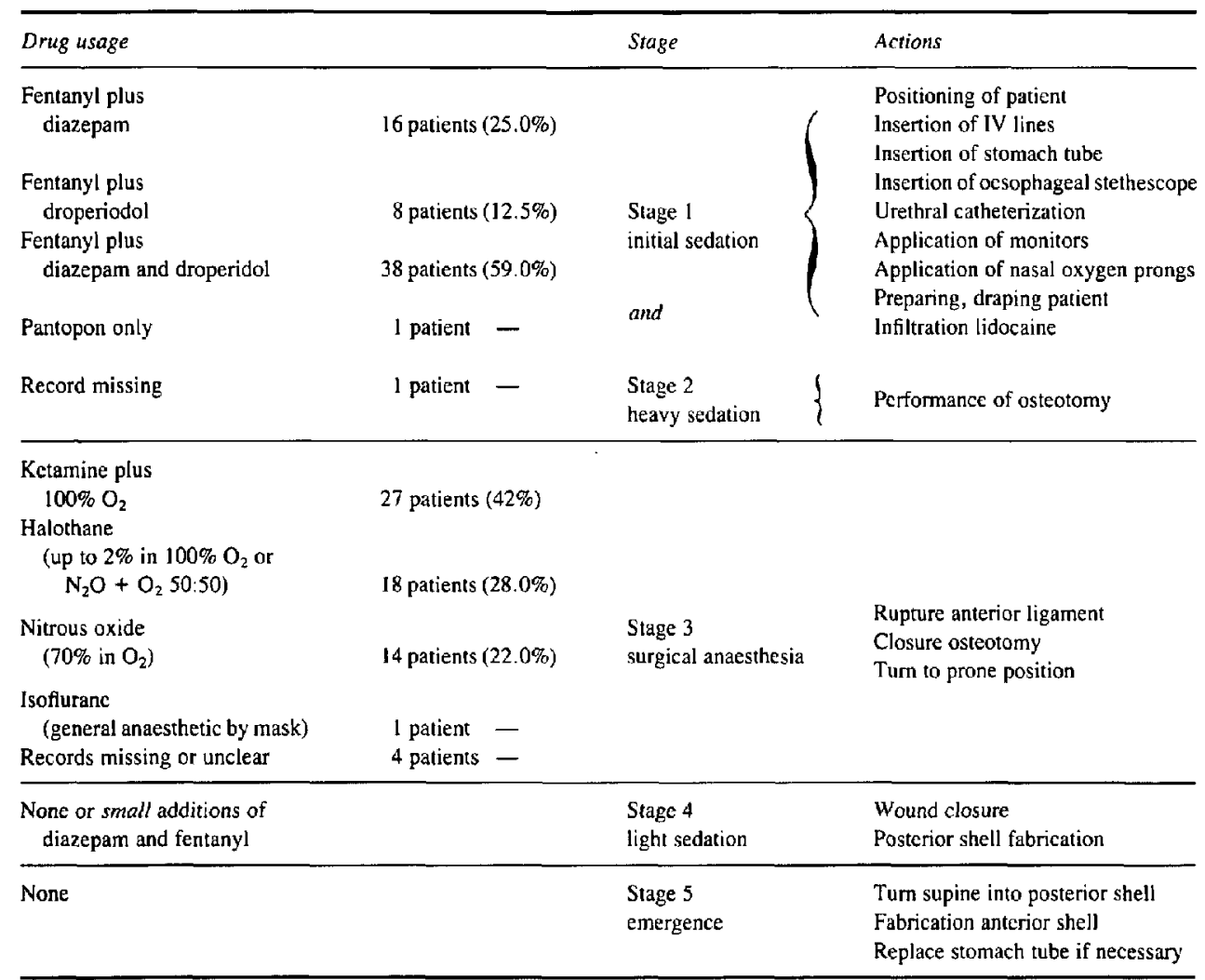

the procedure. However, La Chapelle, ${ }^{5}$ Herbert $^{9}$ and Emneus ${ }^{13}$ used local anaesthesia for the osteotomy. (La Chapelle and Herbert did a second stage surgical division, instead of forcible fracture at the same sitting, of the anterior spinal ligament by an anterior approach for which general anaesthesia was required.) La Chapelle, Adams ${ }^{6}$ and Herbert also used the lateral position for some part of the procedure. Lorenzo, ${ }^{16}$ writing in Portuguese, produced the only article devoted to the anaesthetic management of lumbar osteotomy. His cases were all done under general anaesthesia with endotracheal intubation and with the patient prone.

In 1958 Urist $^{17}$ established the safety and feasibility of performing cervical osteotomy under local anaesthesia in the sitting position. Using Urist's recommendations, Simmons ${ }^{18}$ first performed cervical osteotomy in 1967 at the Toronto East General Hospital, using Urist's recommenda- tions, with the help of Heron ${ }^{19}$ of the Department of Anaesthesia. Local infiltration anaesthesia and sedation were used plus a brief nitrous oxide inhalation for fracture of the neck and correction of the deformity. This experience, and that of others ${ }^{5,9,13}$ prompted Simmons ${ }^{20}$ to attempt lumbar osteotomy under local anaesthesia and sedation in the lateral position. Although the osteotomy could be done with local anaesthesia plus heavy sedation, correction of the deformity, which involved forcible rupture or fracture of the anterior spinal ligament, required a brief period of general anaesthesia. Moreover, a turn to the prone position was required to create sufficient leverage for closure of the osteotomy. Heron managed the first case in May 1969. One per cent lidocaine with epinephrine $1 / 200,000$ was infiltrated and Innovar ${ }^{(1)}$ was used for sedation. Nitrous oxide-oxygen inhalation was used for rupture of the anterior spinal ligament and 
TABLE III Intravenous drug dosages

\begin{tabular}{|c|c|c|c|c|c|c|c|c|c|c|}
\hline & \multicolumn{2}{|c|}{ Fentanyl $\mu g$} & \multicolumn{2}{|c|}{ Diazepam mg } & \multicolumn{2}{|c|}{ Droperidal mg } & \multicolumn{2}{|c|}{ Ketamine ms } & \multicolumn{2}{|c|}{ Ketomine $\mathrm{mg} \cdot \mathrm{kg}^{-1}$} \\
\hline & range & mean & range & mean & range & mean & range & mean & range & mean \\
\hline $\begin{array}{l}\text { Stage } 1 \\
\text { (Initial sedation) } \\
\text { Stage } 2\end{array}$ & $25-250$ & 97.9 & $2.5-20$ & 7.87 & $2.5-7.5$ & 4.17 & - & - & - & - \\
\hline $\begin{array}{l}\text { (Heavy sedation) } \\
\text { Stage } 3\end{array}$ & $75-525$ & 306.4 & $2.5-65$ & 20.0 & $0.0-12.5$ & 3.43 & - & - & - & - \\
\hline $\begin{array}{l}\text { (Surg. anaesth.) } \\
\text { Stage } 4\end{array}$ & - & - & 一 & - & - & - & $40-160$ & 96.67 & $0.8-2.41$ & 1.58 \\
\hline $\begin{array}{l}\text { (Light sedation) } \\
\text { Stage } 5 \\
\text { (Emergence) }\end{array}$ & \multicolumn{10}{|c|}{ None or very minimal doses (diazepan $5 \mathrm{mg}$ or fentanyl $50 \mu \mathrm{g}$ ) } \\
\hline
\end{tabular}

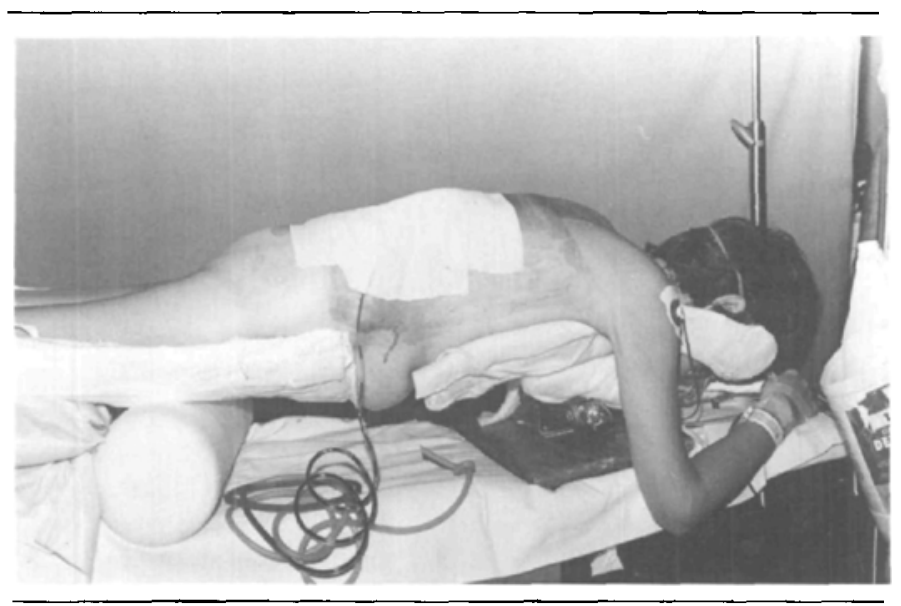

FIGURE 2 Patient lying prone in preformed plaster support moulds at the completion of surgery. Note the modified Honda car jack used to suppor the upper porion.

correction of the deformity. Since then other anaesthetic drugs and methods have been used (Tables II and III).

\section{Patients and methods}

\section{Description of the surgical procedure}

The patient is made as comfortable as possible on the operating table in either the right or left lateral position. After suitable preparing and draping, one per cent lidocaine with epinephrine $1 / 200,000$ is infiltrated into the intended operative site. Usually this will be the $\mathrm{L}_{3}-\mathrm{L}_{4}$ region. The surgeon will have previously diagrammed on lateral $x$-rays the required angles of the wedge osteolomy. The osteotomy is performed as described by Smith-Pedersen ${ }^{4}$ and when the anaesthet ist has induced a suitable level of anaesthesia, as described below, the anterior spinal ligament is forcibly fractured by three-point pressure on the sternum, pelvis and at the operative site. The patient is turned prone into prefabricated plaster moulds (Figure 2 and below) and the operating table is flexed, if necessary, to create sufficient leverage to close the osteotomy and achieve correction of the deformity. Bone grafting is carried out and the correction is secured with steel 
wire loops. The wound is closed and a posterior plaster shell is fabricated on the patient. The patient is turned supine into this shell and an anterior shell is fabricated. Ten to 14 days postoperatively the patient is placed in a Minerva plaster body cast and ambulation is begun. Full union of the osteotomy takes up to nine months.

\section{Patient information and hospital statistics}

Sixty-one patients underwent 64 lumbar extension osteotomies over a 15 -year period $(1969-1983)$ at the Toronto East General Hospital.

Mean patient age was 47 years with a range of 32 to 68 years. Mean patient weight was $62.48 \mathrm{~kg}$ with a range of 37 to $90 \mathrm{~kg}$. Males outnumbered females 46 to 15. (This correlates with the quoted male:female ratio of 3:1 for severe spinal deformity is AS.) Mean time since the onset of symptoms of AS was 26.3 years with a range of 9 to 47 years.

A mean period of 6.2 days in hospital prior to surgery was required to complete preparation of the patient, obtain rheumatology consultation, $x$-rays, photographs, pulmonary function tests and have the support casts fabricated. Total hospital stay averaged 54.7 days with a range of 22 to 181 days. An average of 5.3 days was spent in the intensive care unit. A stomach tube was required for an average of 3.6 days. Average operating room time, including fabrication of posterior and anterior plaster shells, was 258 minutes with a range of 175 to 320 minutes.

Fifty-one patients (84 per cent) were judged, clinically or by pulmonary function testing, to have restrictive lung discase. Sixteen patients (26 per cent) had some degree of chronic obstructive pulmonary disease. Sixteen patients ( 26 per cent) had histories of either peptic ulcer or upper gastrointestinal haemorrhage. Thirty-seven patients ( 61 per cent) had had previous surgery for problems related and unrelated to AS. Previous recorded anaesthetic problems amounted to only three: a "difficult intubation." a blind, awake nasal intubation and a nasal intubation with a fiberoptic nasopharyngeoscope.

\section{Conduct of the anaesthetic}

At the preoperative visit the patient was given a brief description of the procedure and mentally prepared to withstand some pain and general discomfort. Neck mobility, mouth opening and temporoman- dibular joint mobility were assessed. Premedication was not routinely given because the surgeon wanted the patient to stand upright, just before positioning on the operating table, in order to recheck the angles required for the osteotomy. A tracheotomy tray and a fiberoptic nasopharyngeoscope were available in the operating room.

For clarity the anaesthetic management is divided into five stages as outlined in Table Il. Each relates to a phase of the surgical procedure and drug usage (Table III).

Stage 1: Initial sedation for positioning, placement of IV lines and monitors and infiltration of the operative sitc by the surgeon. In this Stage and in Stage 2 (below) 62 of 64 cases received fentanyl plus diazepam andior droperidol (dosage details in Table III). A stomach tube was introduced to drain the stomach and either left in place or removed and replaced with an oesophageal stethescope (see monitoring). The surgeon was provided with lidocaine one per cent with epinephrine $1 / 200,000$, $10 \mathrm{mg} \cdot \mathrm{kg}^{-1}$ of patient weight. The mean dose of liducaine was $641.7 \mathrm{mg}$, range $300-1250 \mathrm{mg}$. Dosage range in $\mathrm{mg} \cdot \mathrm{kg}^{-1}$ patient weight was 5.0-19.6, mean 10.5.

Stage 2: Heavy sedation for performance of the osteotomy (drug dosage details Table III). In this stage drugs were given incrementally, based on patient response. Major patient response criteria were respiratory rate and voiced complaints. Translation of responses into drug dosages was empirical and judgemental. However, it was usually necessary to depress the respiratory rate to $8-10 /$ minute. Oxygen by nasal prongs was administered throughout the procedure. Certain parts of the procedure, such as dissection near nerve roots, were especially painful for short periods. No attempt was made to provide complete freedom from pain since the drug dosages would be excessive for the average level of surgical stimulation.

Stage 3: Surgical anaesthesia for fracture of the anterior spinal ligament and turn to the prone position. Twenty-seven patients (42 per cent) received ketamine intravenously plus oxygen 100 per cent. Ketamine dosage details are given in Table III. Eighteen patients (28 per cent) received halothane in either oxygen 100 per cent or nitrous oxide-oxygen 50:50. Fourteen patients ( 22 per cent) received nitrous oxide 70 per cent in oxygen. 
The problems involved in turning these patients, unconscious, to the prone position are obvious. One problem, in particular, was the provision of safe, functional support which also facilitated maintenance of the airway. The first 31 cases were supported on pillows and bolsters. In 1981 moulded plaster supports were developed. These supports were subsequently used, and found satisfactory, in 33 consecutive cases. These plaster moulds were fabricated preoperatively for each patient, individually, by plaster technicians. The upper part resembles the anterior portion of a Minerva Jacket and the lower part the anterior portion of a hip spica. Figure 2 shows a patient, surgery completed, lying in these supports. Note the modified Honda ${ }^{\circledR}$ car jack supporting the upper portion.

Stage 4: Light sedation for wound closure and fabrication of the posterior plaster shell. Most patients required nothing during this stage; they "coasted" on the accumulated effect of the drugs administered in Stages 1,2 and 3. Occasionally diazepam $5 \mathrm{mg}$ or fentanyl $50 \mu \mathrm{g}$ was administered.

Stage 5: Emergence. Patient turned supine into the posterior shell, which was fabricated in Stage 4, and the anterior shell fabricated. The oesophageal stethescope, if used, was removed and replaced with a stomach tube.

\section{Monitoring}

All patients were monitored with a blood pressure cuff and a Tectronix ${ }^{\circledR}$ digital pulse monitor. Twenty-four patients were monitored with an oesophageal stethescope. An electrocardiograph was used in 29 patients. Forty-seven patients had urine output monitored with the aid of an indwelling urinary catheter.

\section{Fluid requirements}

Colloid: Peroperative blood loss was measured and recorded in 27 ( 42 per cent) cases. The mean measured loss was $1382 \mathrm{cc}$, range 400 to $2800 \mathrm{cc}$. Thirty-eight patients required peroperative transfusion in the range of one to six units, mean 2.8 units and 22 of these also required postoperative transfusion in the range of one to six units, mean 2.48 units. Twenty-six patients did not require peroperative transfusion but 17 of these did require postoperative transfusion in the range of one to four units, mean 2.29 units. Only nine patients (14.7 per cent) did not receive any blood transfusion.
Crystalloid: Lactated Ringers' solution or normal saline was used in a range of 750 to $7500 \mathrm{cc}$, mean $2589 \mathrm{cc}$.

\section{Complications}

Complications related to anaesthetic management (Table IV)

A total of 12 instances (18.75 per cent) of anaesthetic related complications occurred. All were manageable. The most serious was airway obstruction which occurred when the unconscious patient was turned prone in Stage 3. This event was recorded in four cases.

In two cases, during Stage 1, the respiratory rate decreased sufficiently to require a period of assisted ventilation with a bag and mask.

Large venous sinuses were often opened during the osteotomy. In three cases the resulting haemorrhage was brisk enough to cause hypotension and, in one of these, loss of consciousness.

One patient became confused and unmanageable in Stage 1 and required induction of general anaesthesia with a mask and isoflurane. He had a history of consuming $\mathbf{5 2}$ ounces of spirits per week.

The use of ketamine resulted in one hallucinatory reaction peroperatively. We were not aware of its occurrence until described by the patient postoperatively.

\section{Postoperative psychological disturbances}

Thirteen instances (20 per cent) of postoperative psychological disturbances were recorded. They ranged from mild confusion to frank psychoses related to analgesics, medications (cimetidine ${ }^{21}$ ) or alcohol withdrawal. There appeared to be no relationship to the anaesthetic method used in Stage 3 ; seven patients had received halothane or nitrous oxide and six had received ketamine.

\section{Surgical complications}

Twenty-two surgical complications ( 34.4 per cent) were recorded. This figure includes one death which occurred 15 days postoperatively as a result of massive pulmonary embolism. The patient was 42 years old, a smoker and on birth control pills. Upper GI haemorrhage occurred in two cases and ileus, of some degree, in five cases. Other surgical complications ranged from the general (wound infection, phlebitis, urinary retention) to the specific for this 
procedure such as cauda equina injury, lumbar nerve root damage and lumbar dislocation.

\section{Discussion}

\section{Anaesthetic methods}

Inducing general anaesthesia in AS patients is well recognized as a difficult and possibly hazardous procedure. ${ }^{2}$ However, many still have some neck mobility and we have observed that some are fused in the "sniffing position" thought to be ideal for intubation. ${ }^{22}$ Careful preanaesthetic assessment of neck mobility and position, mouth open and temporomandibular joint movement will unmask the truly difficult problems. When significant difficulty is anticipated awake intubation by one of the described methods or with the aid of the fiberoptic scope is mandatory. However, whenever possible local or regional anaesthesia remains the method of choice in these patients.

At first one might have thought that local anaesthesia for a procedure as extensive and as long as a lumbar osteotomy might prove impractical. The routine use of local anaesthesia and sedation in this series was really a surgical request, probably engendered by the widely held belief that local or regional anaesthesia carries a lower respiratory morbidity than general anaesthesia in patients with lung disease. Another compelling argument is the belief that serious neurological complications are avoided if the patient can immediately complain of root pain or demonstrate loss of motor function. Peripheral nerve injury due to pressure points may also be avoided.

Did the avoidance of general anaesthesia decrease the incidence of respiratory complications? The most recent review by McMaster ${ }^{15}$ from the Mayo Clinic lists two cases of pneumonitis in a series of 17 lumbar osteotomies under general endotracheal anaesthesia. We observed none in 64 cases. There is evidence that a cuffed endotracheal tube interferes with mucociliary transport. ${ }^{23} \mathrm{By}$ avoiding invasion of the trachea, maintaining some degree of sighing and coughing throughout the procedure and taking advantage of early patient co-operation with chest physiotherapy we may have reduced the incidence of atelectasis ${ }^{24}$ and respiratory infection.

However, a three- to five-hour procedure under local anaesthesia with heavy sedation plus a brief
TABLE IV Complications related to anaesthetic management

$\begin{aligned} & \text { Airway obstruction on tuming patient prone } \\
& \text { Rapid haemorthage resulting in hypotension }\end{aligned}$
$\quad$ or loss of consciousness
$\begin{aligned} & \text { Respiratory rate too low because of over } \\
& \quad \text { sedation }\end{aligned}$
$\begin{aligned} & \text { Failure to cooperate in Stage 1 } \\
& \text { Peroperative hallucinatory reaction } \\
& \text { Loss of consciousness due to inadequate } \\
& \quad \text { sedation and pain }\end{aligned}$
\begin{tabular}{l} 
Total \\
\hline
\end{tabular}

period of surgical anaesthesia has its own set of problems (Table IV). Monitoring, particularly of the airway and respiration, is vital and can be difficult. ${ }^{25}$ Two patients required mask and bag assistance when their respiratory rates fell too low, as a result of over-sedation. At least four patients developed airway obstruction when turned prone. Each case was relieved by adjusting the patient's position or the introduction of a nasopharyngeal airway. Sudden blood loss may result in loss of consciousness and respiratory obstruction. Moreover, a basic anaesthetic principle may have been violated when a surgical level of anaesthesia was induced (albeit for only a short period) without first securing the airway with an endotracheal tube. In fact, most of the complications listed in Table IV are a result of, and peculiar to, the anaesthetic method used. However, these problems proved manageable in this series.

Experience with airway obstruction led to the abandonment of nitrous oxide-oxygen in Stage 3 in favour of the near 100 per cent oxygen delivery possible with either halothane or ketamine. No clear evidence emerged in this series in favour of either halothane or ketamine for the short period of surgical anaesthesia requried. However, Corssen, in $1971,{ }^{26}$ demonstrated the value of ketamine for patients with difficult, unintubated airways in the prone position. His series consisted of children with severe burns of the head and neck. He felt ketamine's ability to stimulate respiration and to preserve the tone of the tongue ensured an unobstructed airway regardless of the position of the patient.

\section{Use of lidocaine by the surgeon}

The surgeon was provided with lidocaine one per cent with epinephrine $1 / 200,000,10 \mathrm{mg} \cdot \mathrm{kg}^{-1}$ 
patient weight. The anaesthetist was informed if more was required. In one case the dose reached $19.6 \mathrm{mg} \cdot \mathrm{kg}^{-1}$ and in two cases exceeded a total dose of $1000 \mathrm{mg}$. No systemic toxic reactions occurred. There were several reasons for this: 1 . The surgeon avoided an intravenous bolus injection. 2 . The total dose was given over a period of time. 3. At least half the dose was injected subcutaneously, from which site systemic absorption is slow. ${ }^{27} 4$. The patient's threshold to reaction was raised by pretreatment with diazepam. ${ }^{28}$

\section{Postoperative psychological disturbances}

The incidence of postoperative psychological disturbances was significant ( 20 per cent). Other authors $^{8,15}$ have reported psychological disturbances following this procedure. In Law's series ${ }^{8}$ acute psychosis was blamed for an accident which resulted in serious neurological damage leading to paralysis, pneumonia and death. In our series the incidence of this troublesome complication possibly could have been reduced by preoperative identification of alcohol abusers and postoperative pain control which avoids CNS depression (epidural analgesia; see below).

\section{Surgical complications}

Among the surgical complications, the occurence of ileus is noteworthy. Other authors ${ }^{6,8,14}$ have reported paralytic ileus following this procedure. Adams $^{6}$ felt that a true superior mesenteric artery syndrome could develop because the extension correction of the spine might alter relations sufficiently to allow a tense superior mesenteric artery to compress the third part of the duodenum. Whatever the mechanism involved, bowel dysfunction in a patient helplessly trapped by body casts and his own immobile spine is very serious. A stomach tube was used in all cases for preoperative drainage and postoperative decompression and detection of obstruction or GI bleeding. The tube was required for an average of 3.6 days.

\section{Other serious surgical complications reported in the literature}

Fracture of the ankylosed cervical spine: $\mathrm{Law}^{8}$ reported a fracture dislocation of the cervical spine which occurred at some stage in the procedure under general anaesthesia. The ankylosed cervical spine is vulnerable. ${ }^{29}$ Proper support of the head and protection of the neck was one of the goals that spurred the development of the plaster support moulds described in Stage 3 of anaesthetic conduct. In addition, all patients had preoperative cervical spine $x$-rays to rule out incipient atlanto-axial subluxation.

Rupture of the aorta: no instance of rupture of the aorta has been reported during lumbar osteotomy. However, Lichtblau ${ }^{30}$ warned of the theoretical possibility and reported a case of sudden death from aortic rupture during orthopaedic manipulation of an ankylosed spine. The patient had received radiation therapy to the thoracolombar spine for his AS and autopsy showed the aorta to be firmly adherent to the anterior ligament and torn at the point of spinal fracture. He concluded, therefore, that damage to the aorta during lumbar osteotomy was unlikely in the absence of previous radiation therapy.

\section{Conclusions and recommendations}

The development of a safe, practical anaesthetic method for a procedure like this is an evolutionary process. After 64 cases, over 15 years, the sense of where this evolutionary process would lead was just beginning to form. Unfortunately, in October 1983. the surgeon ${ }^{20}$ who had performed all of these cases moved to the U.S.A. Nevertheless, I shall suggest in the next few paragraphs how the method might have been altered and/or improved.

The performance of the osteotomy (Stage 2) in the lateral position, under local anaesthesia and heavy sedation was satisfactory, safe and met surgical requirements. However, the anaesthetic method in Stage 3 was the source of some anxiety since airway control was not ensured. As an alternative, an awake endotracheal intubation, with the aid of a fiberoptic scope if necessary, could be performed at the end of Stage 2. The level of sedation in Stage 2 was certainly deep enough for instrumentation of the airway. The patient could be awakened and extubated just before or just after being turned supine into the posterior plaster shell. Total intubation time would be short and the major advantages of the method would not be lost.

Caudal epidural analgesia (opoid or local anaesthetic) may have a place in the peroperative or postoperative management of pain in these patients. In 1968 Emneus $^{13}$ (Table I) reported that two of his five cases were done with "extradural" anaesthesia. 
In 1981 Deboard $^{31}$ demonstrated that the caudal approach to the epidural space is accessible despite advanced AS and in 1982 Jensen $^{32}$ showed that morphine, by the caudal route, is effective in controlling postoperative pain below the umbilical level.

Lumbar extension osteotomy is an established procedure for the treatment of the severe spinal deformity of advanced AS. Patients are willing to accept the surgical and anaesthetic risks to achieve the functional and cosmetic results afforded by this procedure. This paper describes our attempts to meet the anaesthetic challenge and minimize these risks.

\section{Acknowledgement}

I wish to express my appreciation to Dr. Rogelia Adam for her excellent translation of articles from Portuguese and Spanish.

\section{References}

1 Rodnan Gerald $P$, Schumacher $H$, eds. Ankylosing Spondylitis. I $n$ : Primer on Rheumatic Diseases. Atlanta, Ga: The Arthritis Foundation, 1983: Chapter 27, page 85.

2 Edelist $G$. Principles of anesthetic management in rheumatoid arthritic patients. Anesth Analg 1964; 43: $227-31$.

3 Calin A. Spondylarthropathies. In: Medicine. Sci Am 1983. Rheumatology No. 15, iii.

4 Smith-Petersen $M N$, Larsen $C B$, Aufranc $O E$. Osteotomy of the spine for correction of flexion deformity in rheumatoid arthritis. J Bone Joint Surg 1945; 27: 1-11.

5 La Chapelle EH. Osteotomy of the lumbar spine for correction of kyphosis in a case of ankylosing spondylarthritis. J Bone Joint Surg 1946; 28 : $851-8$.

6 Adams $J C$. Technique, dangers and safeguards in osteotomy of the spine. J Bone Joint Surg 1952; 34B: $226-32$.

7 Nunsiato A. Osteotomia de la Columna. Prensa Med Argent 1948; 35: 1536-49.

8 Law WA. Osteotomy of the spine. J Bone Joint Surg 1962; 44A: 1199-206.

9 Herbert $J$-J. Vertebral osteotomy for kyphosis, especially in Marie-Strumpell arthritis. J Bone Joint Surg 1959; 41A: 291-302.

10 Scudese V, Calabro JJ. Vertebral wedge osteotomy. JAMA 1963; 186: 105-9.
11 Goel MK. Vertebral osteotomy for correction of fixed flexion deformity of the spine. J Bone Joint Surg 1968; 50A: 287-94.

12 Kallio KE. Osteotomy of the spine in ankylosing spondylitis. Ann Chir Gynaecol Fenn 1963; 52: 515-9.

13 Emneus $H$. Wedge asteotomy of the spine in ankylosing spondylitis. Acta Orthop Scand 1968; 39: $321-6$.

14 MeMaster MJ, Coventry MB. Spinal osteotomy in ankylosing spondylitis. Mayo Clin Proc 1973: 48: 476-86.

15 McMaster PE. Osteotomy of the spine for fixed fiexion deformity. J Bone Joint Surg 1962; 44A: 1207-16.

16 Lorenzo AV, De Camargo FP, De Souza JA. Anestesia para a osteotomia da coluna. Revista Brasileira De Anestesiologia 1966; 16: 77-83.

17 Urist MR. Osteotomy of the cervical spine. J Bone Joint Surg 1958; 40: 833-43.

18 Simmons EH. The surgical conection of flexion deformity of the cervical spine in ankylosing spondylitis. Clin Orthop 1972; 86: 132-43.

19 Harris AG, Heron JS, Renwick WA. Anaesthesia for posterior cervical osteotomy. Can Anaesth Soc J 1975; 22: 84-90.

20 Simmons $E H$. Surgery of the spine in rheumatoid arthritis and ankylosing spondylitis. In: Evarts CM, ed. Surgery of the Musculoskeletal System. New York: Churchill Livingstone, 1983; Vol 2: Sect 5, Chap 4: 107-31.

21 Barnhart CC, Bowden $C L$. Toxic psychosis with cimetidine. Am J Psychiatry 1979; 136: 725-6.

22 Dripps $R D$. Eckenhoff JE. VanDam LD. Introduction to Anesthesia. 3rd ed. Philadelphia: WB Saunders, 1967: 169.

23 Sackner MA. The effect of cuffed endotracheal tubes on tracheal mucous velocity. Chest 1975; 68: $774-7$.

24 Rigg J. Pulmonary atelectasis after anaesthesia: pathophysiology and management. Can Anaesth Soc J 1981; 28: 305-20.

25 Jain U, Gold MI. Monitoring respiration during regional anesthesia. Anesthesiology 1984; 60: 166.

26 Corssen $G$. Dissociative anesthesia in the severely bumed child. Anesth Analg 1971; 50: 95-102.

27 Covino BG. Pharmacokinetics of local anaesthetic drugs. In: Prys-Roberts C, Hug CC Jr, eds. 
Pharmacokinetics of Anaesthesia. Blackwell Scientific Publications, 1984; 273.

28 deJong $R H$, Heavner JE. Diazepam prevents local anesthetic seizures. Anesthesiology 1971; 34: 52331.

29 Bergmann EW. Fractures of the ankylosed spine. J Bone Joint Surg 1949; 31a: 669-71.

30 Lichtblau PO, Wilson PD. Possible mechanism of aortic rupture in orthopaedic correction of theumatoid sponylitis. J Bone Joint Surg 1956; 38a: 123-7.

31 Deboard JW, Jawajar NG, Guilford WB. Caudal anesthesia in a patient with ankylosing spondylitis for hip surgery. Anesthesiology 1981; 54: 164-6.

32 Jensen PJ, Siem-Jorgensen $P$, Bang Nielsen $T$, Wichmand-Nielsen $H$, Wintherreich $E$. Epidural morphine by the caudal route for postoperative pain relief. Acta Anuesthesiol Scand 1982; 26: 511-3.
Résumé

Soixante-quatre cas d'ostéotomie lombaire postérieure d'extension faits au "Toromto East General Hospital" entre les années 1969 et 1983 sont revus. La conduite anesthésique est présentée. La procédure a été accomplie avec infiltration a' anesthésique local, sédation lourde et une périude brève d'anesthésie générale induite avec le protoxyde d'azote, l'halothane ou la kétamine. Cinq étapes de la conduite anesthésique ont été considérées chacune en relation avec la phase de la procédure chirurgicale et le médicament utilisé. Une méthode de soutien de ces patients déformés en position ventrale darts un moule de plâtre est décrite. Les complications chirurgicales et anesthésiques ainsi que les perturbations psychologiques post-opératoires sont décrites et discutées. Il est suggéré que l'administration d'opiacés par voie caudale êpidurale ou l'analgésie par des anesthésiques locaux soient explorées afin de faciliter la conduite thérapeutique chez ces patients. 